\section{REFERENCES}

1. Australian National Council on AIDS and Related Diseases Hepatitis C Sub-committee, Hepatitis C Virus Projections Working Group. Estimates and Projections of the Hepatitis $C$ Virus Epidemic in Australia. Sydney: National Centre in HIV Epidemiology and Clinical Research, 1998. p.11.

2. National Centre in HIV Epidemiology and Clinical Research and NSW Health Dept. Estimates and Projections of the Hepatitis C Virus Epidemic in NSW. Unpublished report, 1999. p.1.

3. Lowe, D, Cotton, R. Hepatitis C: a review of Australia's response. Canberra: Commonwealth Dept of Health and Aged Care, 1999.
4. Legislative Council Standing Committee on Social Issues. Hepatitis C: the Neglected Epidemic. Sydney: NSW Parliament, 1998. W

Further information about the NSW Health Hepatitis $C$ Public Awareness Campaign can be obtained from Brent Mackie, AIDS/Infectious Diseases Branch, NSW Department of Health, Locked Bag 961, North Sydney NSW 2059. Telephone: (02) 9391 9247. Email: bmack@doh.health.nsw.gov.au.

\title{
LETTER TO THE EDITOR
}

\section{DEAR EDITOR}

The NSW Public Health Bulletin has helped to bring together a group of researchers to investigate the links between cardiovascular disease and periodontal disease. Staff at the Royal North Shore Hospital and the United Dental Hospital are joining forces in the Pericar Study to study the effect of periodontal treatment on haemostatic risk factors for cardiovascular disease in patients with advanced periodontal disease.

The Pericar Study was developed as a direct result of the recent publication of the four-part oral health series in the Bulletin during 1999. The papers in the series successfully promoted a greater awareness of oral health issues in the wider health community and facilitated interaction and discussion between health professionals.

We thank the Bulletin for providing the forum that resulted in this exciting research opportunity with its implications for health care.

\section{Geoffrey Tofler}

Department of Cardiology

Royal North Shore Hospital

\section{Barbara Anne Taylor}

Department of Periodontics

United Dental Hospital of Sydney

\section{ERRATUM}

In the January-February issue of the NSW Public Health Bulletin (Volume 11, Numbers1-2, page 13) the contact list for Women's Health Coordinators in the Area Health Services had an incorrect table heading. The heading 'Injury Program Manager' should have read 'Women's Health Coordinator'. The editor apologises for this error. 